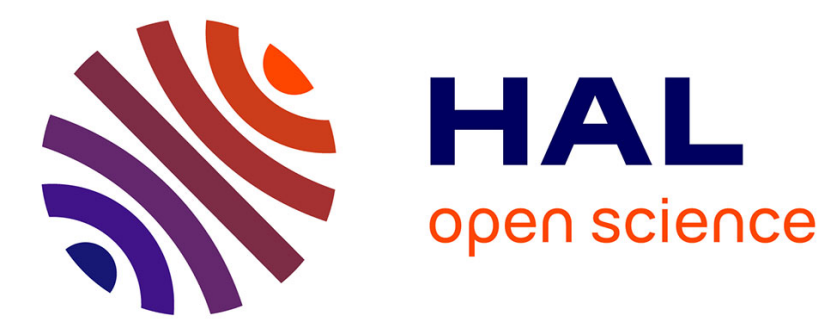

\title{
Are French networks different?
}

Michel Grossetti

\section{- To cite this version:}

Michel Grossetti. Are French networks different?. Social Networks, 2007, 29, pp.391 - 404. 10.1016/j.socnet.2007.01.005 . halshs-01397154

\section{HAL Id: halshs-01397154 https://shs.hal.science/halshs-01397154}

Submitted on 15 Nov 2016

HAL is a multi-disciplinary open access archive for the deposit and dissemination of scientific research documents, whether they are published or not. The documents may come from teaching and research institutions in France or abroad, or from public or private research centers.
L'archive ouverte pluridisciplinaire HAL, est destinée au dépôt et à la diffusion de documents scientifiques de niveau recherche, publiés ou non, émanant des établissements d'enseignement et de recherche français ou étrangers, des laboratoires publics ou privés. 


\title{
Are French Networks Different? ${ }^{1}$
}

\author{
Michel Grossetti, Version 7d Oct 262005
}

Michel Grossetti, 2007, «Are French networks different? », Social Networks, Vol. 29, n³, pp. 391-404.

\begin{abstract}
Claude S. Fischer's survey of social networks in northern California was transposed to the Toulouse area of southwestern France. This article compares the results obtained in this new Toulouse study with Fischer's findings. It finds somewhat larger networks but similar heterogeneity.
\end{abstract}

\section{Introduction}

In 1976, Claude S. Fischer launched a large-scale study of personal networks to test the theory that community ties were experiencing a decline as the result of mass urbanization (Fischer, 1982). It demonstrated that the opportunities for obtaining social support have not decreased in either urban or rural contexts. Together with Barry Wellman's East York, Toronto studies in the same era (Wellman, 1979; Wellman and Wortley, 1990), Fischer's study has become a classic reference for research on personal networks. However, these studies have shown that urban networks take on a slightly different structure: in particular, a lower density.

To what extent can one transpose the results obtained in North America in the 1970s into other contexts? A few years ago, Yossi Shavit used Fischer's survey method for a comparative study in the Haifa area of Israel (Fischer and Shavit, 1995). The results corresponded to Fischer's original study:

In many respects, the networks did not differ much. Israelis, however, had networks that were denser than the Americans' networks - and denser than networks reported from elsewhere, too (Fischer and Shavit, 1995, p. 129, abstract). ${ }^{2}$

Would one find similar results with a European sample and, in particular, a French sample? In a book edited by Barry Wellman (1999), Alexis Ferrand, Lise Mounier and Alain Degenne studied different types of ties: friendship, love, trust, reciprocity. They summarize the essential characteristics of French society and its networks:

French society has the dual property of (1) strongly and rigidly reproducing differences between categories, but (2) synchronically linking them by means of multiple relational substructures with overlapping effects. If this is so, then the strong consensus that underlies the popular view of a 'French' social order

\footnotetext{
${ }^{1}$ Michel Buret, from the Agence d'Urbanisme de l'Agglomération Toulousaine (Urbanism Agency for the Toulouse Metropolitan Area), helped me determine the survey sectors. Marina Jean and Myriam Dereix contacted the respondents and fill the questionnaires with them in face to face interviews. Various other people helped in determining the sample and in coding the data. Rebbekah Irving helped me to put the first version of this text into English. I am also grateful for the advice of Alexis Ferrand, and for the editorial assistance of Julie Wang, Barry Wellman, Alexis Kane Speer and Natalie Zinko. This paper has been supported by the Plan Urbanisme Construction et Architecture (French Ministary of Equipement) and the Centre de Prospective de la Gendarmerie Nationale (French Ministry of Defense).

2 "Elsewhere" refer to a systematic comparison of different studies (table 3, page 139), in Canada (East Yorkers), England (London Neighboroods, by Willmott), China (Ruan), Detroit (Laumann), etc.
} 
may only be the effect - at the level of cognitive representations and cultural values - of an inability to think of oneself (and one's strata) as being cut off from the rest of society (Ferrand, et al., 1999, p. 215).

My study of personal networks in the Toulouse area aims to estimate the possibility of transposing the results of North American surveys onto a French sample. I chose Fischer's method to test this transposition for various reasons, including the fact that it allows for the gathering of information about "weaker" ties as well as "strong" ones. However, the Toulouse survey is a transposition, and not a mere replica, of the northern California survey. Although the name generators and the general logic of the procedure remain the same, the questionnaire is different and certain parts of the procedure were modified.

I begin by describing the methods used in Toulouse and the data collected. Next, I systematically compare different indicators. In the conclusion, I interpret the general convergence in the results obtained.

\section{Transposing Methods}

\section{Fischer's Study}

Fischer's survey was carried out between 1977 and 1978 in different parts of northern California, including San Francisco, Sacramento, and several rural counties. Its random sample of 1,050 respondents was spread over various contexts, from an urban center to rural areas.

The questionnaire consisted of nine name generators, combining scenarios of exchanging favors ("When people go away for a while, they sometimes ask someone to take care of their house - for example, to water the plants, pick up the mail, feed a pet or just check on things, etc.") and descriptions of specific practices (having had someone over for lunch or dinner in the last three months). These name generators produce information about different types of relations. For example, the question about asking respondents who takes care of their homes when they go away results in lists of network members who are generally less intimate than the lists of network members elicited by a question about the network members with whom the respondents discuss personal problems.

Taken together, all of the nine name generators led the respondents to list a mean of 12.8 names. The interviewers then asked the respondents to complete the list ("Is there anyone who is important to you who doesn't show up on this list?") and obtained a mean of 5.7 additional names. Summing these two lists leads to a total of 18.5 ties in the average northern Californian's network.

Each respondent was asked additional questions about a sub-sample of these ties. For each respondent, the interviewers selected a subsample of names by choosing the first name in five of the nine lists obtained as answers to the name generators. A matrix of ties among network members was also filled out, allowing us to estimate the density of the personal networks.

These procedures provided four groups of data:

- The sample of respondents (P1)

- All of the network members the respondents mentioned (P2)

- A subsample of 5 network members per respondent (P3)

- A matrix of interconnections for each network (not analyzed here) 
Figure 1 summarizes the procedure, as well as several differences between the two surveys. The arrows figure the report of information from one data corpus to another. The first coded corpus is P1. Then, answers to the name generators were used by the California team to make the $\mathrm{P} 2$ corpus. Calculation from $\mathrm{P} 2$ were used to fill $\mathrm{P} 1$ with network indicators.

We used a somewhat different procedure in Toulouse. We did not make the P2 corpus a separate data set. Rather, we calculated some indicators directly from P1 (network size, density). In both studies, a P3 corpus was created from the answers to questions on the subsample of relations. Figure 1 shows the relationship of the samples to each other.

\section{$>$ FIGURE 1 HERE <}

\section{Transposition to Toulouse}

Setting: Toulouse is a city in the southwest France with a population of approximately 750,000 in its metropolitan area. It is the capital of a rural region with no other large cities. The second largest city in the region has only 75,000 inhabitants. Toulouse is an important center for the technological industry: aeronautics (it is the central place of the Airbus), space, transportation electronics \& information technology. Hence, there is a considerable population of researchers, engineers, and technicians.

We chose our sample in four sectors of the metropolitan area and a rural canton:

1. The center of Toulouse ( 2 streets): more or less inhabited by the upper class ( 99 respondents);

2. Muret, a community southwest of the metropolitan area (4 streets): working class (100 respondents);

3. Saint-Jean, in the western part of the metropolitan area (3 streets): middle class (51 respondents);

4. Castanet, in the southwestern part of the metropolitan area (3 streets): upper-middle class (high proportion of engineers, 50 respondents);

5. Various small rural communities in the Tarn Department near Graulhet, more than an hour outside of Toulouse (99 respondents).

The sample is designed to have a good equilibrium between social and spatial contexts. It is a good representation of the Toulouse region population.

Name Generators: 1. When people go away for a while, they sometimes ask someone to take care of their house - for example, to water the plants, collect the mail, feed the animals or just check on things. If you went away, would you ask someone to take care of your house for that period of time?

2. Some people never talk about their work or their studies with others, neither at work (or university) nor elsewhere. Other people discuss things like the decisions they have to make, professional problems they have to solve, and ways to improve how they work. Is there someone you talk to about your work?

3. In the last three months, have friends helped you with household tasks like painting, moving furniture, cooking, washing or doing major or minor repairs?

4. In which of the following activities have you participated in the last three months?

- Having someone over for lunch or dinner

- Going to someone's house for lunch or dinner 
- Having someone over for a visit

- Going to someone's home for a visit

- Meeting someone you know at a place outside the home (e.g. restaurant, bar, park, club, etc.)

- Other activities:

If so, can you tell me with whom you shared these activities?

5. Sometimes, people discuss recreational activities or pastimes they have in common. Do you discuss this type of thing? If so, with whom do you do it regularly? home)?

6. Do you have a partner or a best friend, whom you meet very often (outside the

7. When you have personal problems - for example, regarding someone close or something important to you - with whom do you discuss them?

8. Oftentimes, people rely on the advice of someone they know in order to make important decisions - for example, decisions regarding family or work. Is there someone whose advice you would consider seriously in making important decisions? If so, whose advice would you consider?

9. If you needed a large amount of money, what would you do: would you ask someone you know to loan it to you; would you ask for a loan at a bank; would you do something else? What would you do in an emergency situation - is there someone (else) you would most likely ask for some or all of the money?

Surveying: The list of people to be contacted was constituted using the telephone book of the main French phone company, France Télécom. We constructed a random sample of adults (from 18 to 83) in the chosen areas. A letter was sent to the selected individuals before the interviewers made appointments by telephone. The two interviewers divided the areas to be studied between them.

Although the basic protocol and the questionnaire worked satisfactorily, we had to overcome a few difficulties. First, we could not use our sampling method for the rural area. The interviewer had to make appointments by telephone without the aid of the preliminary letter that we had sent to the urban zones. Second, the survey in zone 2 (working class) proved difficult to administer. There were numerous refusals and difficulties in understanding certain parts of the questionnaire. Questionnaires were returned to us from late February 2001 to early July of the same year. Approximately two-thirds of the contacted persons agreed to be interviewed. The main problem for others was finding time to meet with our investigators.

The 399 respondents (P1) listed 10,932 people in their networks (P2); 1,624 of whom were the object of additional questions (P3). Men and women appear about equally in the samples of respondents and in the overall $\mathrm{P} 2$ and $\mathrm{P} 3$ lists of network members.

Fischer's survey had been financed by public health research organizations to investigate if network members were sources of psychological problems and social support. This helps to explain the high number of questions dealing with the "psychological mood" of the respondents. Such matters did not interest me at all. Therefore, all that we kept from Fischer's survey were the sampling and contact method, the name generators, and the procedure for selecting people for additional questions. 
We made several changes to Fischer's original design. First, our interviewers did not necessarily favor the man when a family household was contacted. Second, we did not ask for the full names of network members, but simply their first names or pseudonyms. Third, we added questions about relations that had "disappeared": people previously associated with on a regular basis, but not in the past two years.

We also made some modifications involuntarily. The most significant one concerns a sentence that we had overlooked in Fischer's 1982 book:

In answer to each question, respondents named as many people as they wished, but interviewers generally only recorded the first eight names ${ }^{3}$ (ten for the question on social activities) (p. 36).

However, our interviewers noted all of the names, rather than the first eight. This reaped different results: we obtained the names of 27 persons in our survey instead of Fischer's 18.5. As it turned out, this error proved useful because the alteration reveals interesting results that were not apparent in Fischer's study.

For our own analysis, we recoded the Toulouse data by truncating the lists using the method of the interviewers in the Fischer's northern Californian survey. This made it possible to compare the number of names obtained by Fischer's more restrictive method and our own. The subsample of relations (P3) was not modified since it deals with the five first names mentioned in response to some of the generators. I restrict myself here to the most common indicators.

\section{Size and Density of the Networks}

The procedural modification mentioned above (collecting all the names instead of limiting the lists to the first 8 or 10) has the advantage of making it possible to compare the distributions obtained using the two procedures. When one truncates the lists as was done in the California survey, one gets a distribution of the number of names that is approximately Gaussian. The Toulouse data, recoded to simulate the procedure of limiting the lists, contained a median of 15, and a mean of 14.6. This is slightly higher than Fischer's mean of 12.8. Network density is also similar in Toulouse and California (Table 1).

\section{$>$ Table 1 about here: Size and density <}

The slight difference in network size may be explained in many ways, but I prefer to maintain that the size scale is similar. My idea is that the main information is the similarity in mean size because there are too many slight differences in the methods and the social contexts to provide a good explanation of the slight difference. In these data, the graphic normality tests (P-P plot) are convincing regarding the general appearance of the distribution, even though a parametric - and thus more demanding - test does not establish with certainty the normality of the distribution. On the other hand, when the number of relations is calculated on the basis of spontaneous answers to the name generators, it is distributed more or less as a log-normal law. The median of 20 is clearly lower than the mean of 23.4. Here again, the graphic tests are convincing.

This difference in statistical distribution is interesting because the two types of distributions indicate different social phenomena. When we are faced with a normal law, it generally means that numerous independent causes produce variations of a "normal" value. The weight or the size is distributed in this way. By contrast, log-normal laws, thus named

\footnotetext{
${ }^{3}$ My italics. I would like to thank Alexis Ferrand for alerting me to this problem.
} 
because their logarithm is distributed like a normal law, are rather frequent in cases of cumulative effects. For example, revenues, salaries and scientific publications tend to be distributed log normally. This suggests that personal networks behave as a resource - which is an argument in favor of the notion of "network capital," i.e., interpersonal social capital (Sik and Wellman, 1999). The networks are neither egalitarian nor random.

This interpretation (nothing very new) is reconfirmed by the correlation between the number of names mentioned and the respondents' socioeconomic status, no matter how it is evaluated. For example, as in the California survey, the average number of relations varies by the respondents' education level (Table 2). The more educated people are, the larger their personal networks. The number of relations is distributed as a kind of resource, correlating with the other resource indicators such as education level. ${ }^{4}$ Thus, network capital reinforces the inequalities produced by the other forms of social resources.

\section{$>$ TABLE 2 HERE <}

The number of relations does not significantly differ between men and women once we account for variations in education level and age. With respect to age, the number of relations are generally stable or increase slightly until the age of 65 , when they drop rather suddenly, perhaps reflecting widespread retirement from the workforce.

We asked respondents to describe their role relationships by offering them categories similar to those used in the northern California study. The resulting name distributions are similar (Table 3). Kin, including adult household members, represent about 40 percent of the relationships, both in Toulouse and in northern California.

\section{$>$ TABLE 3 HERE <}

For the rest of the roles, discrepancies can be attributed to the coding method used. When respondents checked off more than one box (neighbor and friend, for example), Fischer reallocated them to a single category according to the following hierarchy: kin, then co-workers, then neighbors, then members of organizations, then "others" and, finally, "friends". By contrast, we coded all of the different categories checked off, which enlarged the rather elastic category of "friends". In the names selected for additional questions (P3), the descriptive "friend" was associated with another category in a third of the cases. If we transpose this ratio onto the total sample (i.e., we keep only two-thirds of the "friends"), we get 28 percent of "friends only," which brings us close to Fischer's findings. Once the difference in role elicitation is taken into account, the main statistical difference is with "neighbor," which is less frequently mentioned in the Toulouse survey $(5 \%$ is compared with $10 \%$ for Californians).

As Fischer noted, the differences between people with different levels of education in the number of names mentioned is essentially due to certain types of relations: those linked to professional activities or simply friendship relations. The number of network members identified as kin does not vary linearly with education level. It begins to decrease slightly between those who do not have a baccalauréat ${ }^{5}$ and those who do, but it goes back up again for those with higher education levels.

The percentage of kin in these networks gradually diminishes as the total number of relations increases. ${ }^{6}$ The Toulouse data generally show an increase in the number of kinship relations with increasing education level. The most highly educated respondents have the

\footnotetext{
${ }^{4}$ The result is the same with the socio-professional category.

${ }^{5}$ This diploma is generally obtained at age 18 after 12 years of education.

${ }^{6}$ The results are similar with the size-corrected data.
} 
most kin in their networks. There are no significant differences between socioeconomic categories in the number of kin, although executives and the higher intellectual professions name the highest number of kin. This contrasts with the findings of François Héran (1987, 1989) that executives have a lower proportion of relations with parents.

\section{Multiplexity}

A single name may reappear several times in answer to different generators. This means that a person is possibly involved in various types of interactions with the network member. The variety of contexts in which a relation may arise is often designated by the terms "multistrandedness" and "multiplexity": the extent to which a relation is either versatile or specialized.

One simple and generally useful indicator for the tendency to mention the same network members more or less frequently can be calculated by dividing the sum of all the names - given separately in answer to the generators and including repeated names in the sum - by the total number of different names (excluding additions). The resulting number varies between 1 - a highly specialized network in which no name repeats in response to different generators - and 7.6 - a network in which almost all network members provide almost all types of support. The mean of 1.7 indicates the general situation of specialized networks, similar to the mean multiplexity (1.6) of the northern California sample (Fischer, 1982, p. 141-142). Similar to the Californians, the tendency for the Toulouse respondents to mention the same persons for several generators increases with age as relations become more specialized over time.

\section{Homophily}

Homophily is the likelihood of people to have network members consisting of people with characteristics similar to their own. The northern California survey showed that homophily was more advanced in urban environments than in rural ones. Thus urban relations were more segregated: young people associated less with old people, high-level graduates less with those who have little education, etc.. In Toulouse, we measured the tendency to segregate relations by cross-checking the characteristics of the respondents with the characteristics of the members of their networks.

Not surprisingly, we find a strong tendency for people to choose others similar to themselves. Men associate more often with men (62 percent) and women associate more often with women (62 percent too). ${ }^{7}$ This is true at all ages and socioeconomic levels. The most educated people associate with the most educated, and executives associate more with other executives (see also Ferrand, et al., 1999). As for indicators of education level and profession, the homophilic tendency is more marked at the ends of the spectrum. The middle categories (intermediate professions, a two-year university degree) do not distinguish between people with whom they associate and may be chosen by all of the other categories.

The same tendency is also seen as far as age is concerned: homophily is stronger at the ends of the spectrum. People between 46 and 65 years demonstrate markedly less homophily. Women have less age homophily than men. .Relations within the same age group tend to be more multiplex than relations among people of different ages.

We created homophily indicators for each of the social support variables by separating cases in which the respondent "namer" and the network member "named" are in the same category from those in which they are in different categories. Certain generators are associated with homogenous relations: excursions and recreation. Others are rather

\footnotetext{
${ }^{7}$ Note that Bastani (2006) reports similar gender segregation in Tehran, Iran.
} 
indifferent as to difference in age, sex or social position: home maintenance, housework, advice in making decisions, loaning money.

Differences in homophily are small between the urban locales of Toulouse that we surveyed. The rural zone near Toulouse is less homophilic in sex and age. Rural respondents name more people of different ages and gender, possibly because of a lower number of people with similar ages, genders, and other social characteristics. Contrary to what was observed in northern California, the rural Toulouse sample does not differ from the urban locales in homophilic relations according to education level. It is likely that this segregation by education in the rural zone reflects its social composition, juxtaposing traditional rural people (farmers, shopkeepers, etc.) with the "neo-rural": more highly educated people who are living in a rural environment after having lived in large cities.

\section{Social Support}

Social relations are resources capable of being mobilized in various situations. In situations of sickness, unemployment, and family breakups, such relationships are often keys to overcoming such difficulties. Hence, the absence or scarcity of relations mentioned by a respondent indicates a lack of resources that could lead to the situation becoming worse if a problem occurs.

In the California survey, Fischer used answers to the name generators to construct indicators of three types of social support:

- Advice: the sum of names of people living outside the household given in response to the questions about discussing personal problems and asking someone's opinion (with three categories: $0=$ "inadequate"; $1=$ "marginal" and $2+=$ "adequate").

- Companionship: the sum of names of people living outside the household given after questions on social and recreational activities (with three categories as well: 0 or $1=$ "inadequate"; 2 or $3=$ "marginal" and $4+=$ "adequate").

- Practical support: the sum of names of people living outside the household given in answer to questions on home maintenance, help with housework, and discussions of work and loans (with the same division into three categories as the previous indicator).

I constructed the same indicators for the Toulouse study. Companionship is rather different in the two studies, with a lower percentage of isolated individuals in Toulouse (Table 4). The difference is weaker for the two other indicators.

\section{$>$ TABLE 4 HERE <}

Men are more likely to say that they only have a few advice-giving relations. The percentage of men getting advice increases regularly with age: not one respondent under age 25 named a network member as a person who gives advice whereas 15 percent of those over 65 did so. The companionship indicator does not mean much to us because almost all of the respondents mention at least two persons. There are distinct differences between occupational categories in the number of people who give practical help. Most respondents mention two or more network members. It is only among low-level employees, blue-collar workers, or those with no work activity that there are respondents who mention only one network member providing practical help or none at all. It is the same for education level: the higher it gets, the fewer respondents mention only one network members or none at all.

The proportion of respondents giving very few names increases markedly with age. Hence, age is the only one of the three indicators that correlates with the resource indicators 
and that can possibly relate relational poverty to more impoverished socioeconomic circumstances.

\section{Spatial Dispersion of Relations}

Fischer measured the spatial dispersion of networks using two criteria based on travel time by car:

We used five minutes because it approximates the local community - a small town or a section of a large city. We used one hour because it roughly delimits the outside commuting distance or casual visiting distance, and it covers approximately a metropolitan area or a rural county (Fischer, 1982, p. 158).

In his survey, the interviewers asked respondents to say whether each person mentioned lived less than five minutes or more than one hour away from their own residence.

In our survey of Toulousains, we asked this kind of question in more detail for only the P3 sub-sample, asking respondents to report about each network member's place of residence, the usual travel time between their homes, and the transportation method habitually used. We repeated the questions for the person's workplace, and we also crosschecked the respondents' homes and workplaces against their network members' homes and workplaces.

Comparisons with the California survey are limited, since not exactly the same relations are taken into account. In the California survey, one-fourth of network members reside at a maximum of five minutes from the respondent's homes and two-thirds live a maximum of one hour away (Table 5). Using the same categories, the Toulouse relationships are more local: 28 percent are between 0 and 5 minutes away, 55 percent between 6 minutes and an hour away and 17 percent more than one hour away. However, one hour's drive means a space slightly larger than the Toulouse metropolitan area of 750,000 inhabitants, 400,000 of whom live within the Toulouse city limits. By contrast, the San Francisco metropolitan area (in northern California) is about 10 times more populated, making more people available for connectivity within an hour's drive.

\section{$>$ TABLE 5 HERE <}

In Toulouse, we coded the place of residence of the network members by dividing the metropolitan area into segments. This enabled us to calculate the proportion of network members who are located in the metropolitan area as defined by its administrative limits: 71 percent. We thus get 12 percent of network members residing beyond the limits of the metropolitan area yet less than one hour away. Within the Toulouse metropolitan area (if both partners of the relations live there), the travel time between the homes of respondents and network members is 20 minutes (or less) for 80 percent of the ties. One might think that one hour of travel time is a less relevant criterion for Toulouse in 2001 than for northern California in 1977. In Toulouse, an hour's drive brings you far from the urban context, and the metropolitan area (as defined by the French National Institute for Statistics and Economic Studies [INSEE) on the basis of the continuity of buildings] is a better approximation of the space of the city.

Thus, around 80 percent of the Toulousains' network members live less than one hour away and 70 percent live in the metropolitan area. Slightly less than one third (31 percent) reside within five minutes, with this rising to 40 percent when taking into account the shortest amount of time among all of the possible trips between the homes and the workplaces of the respondents and the members of their networks. 
To get a clearer understanding, we can use other measurements, such as distances between workplaces, between home and work, etc. Yet, using these other measurements do not change anything for people residing more than one hour away from the homes of their network members. Less than 3 percent of them work less than one hour away or live less than one hour away from the respondents' workplaces. In 13 percent of the relations, when travel time between homes is from 20 to 60 minutes, there exists a shorter distance - between two workplaces, for example - that is less than the travel time between homes although still more than 20 minutes away. Workplaces can be closer than homes if the homes are less than one hour apart. However, one hour of travel time is an upper limit between the "local" (where daily visits at home or at work are easy) and the "non-local", at least for the criteria related to home-work distance. Thus, Toulousains' personal networks are more "local" than those of northern Californians. Interestingly, one hour's travel seems to be an important tipping point for contact and support for the Torontonians surveyed in 1979 (Mok and Wellman, 2006).

\section{Conclusions}

My foray of transposing a method used in another country 25 years ago has been based on the hypothesis of a certain stability in the structure of personal networks. However, I did not expect to discover such marked convergences between the personal networks of the Toulousains in 2001 and the Californians in 1977-1978 (Table 6).

\section{$>$ TABLE 6 about HERE <}

The convergence in the total number of names is a bit of a methodological effect since Fischer chose to truncate the lists in northern California. Applying the same coding made it likelier that our findings would be close to his. The fact that we found a few more persons, even after this adjustment, probably arises from a smaller number of very isolated persons in our study (see the discussion on social support). The similarity in the number of names mentioned would be more convincing if the American interviewers had written down all of the names mentioned as we did.

Convergence in densities was a little less predictable. In the Toronto survey, Wellman (1979) found the mean density to be 0.33, surprisingly lower when dealing with strong ties that are supposed to be more interconnected according to Granovetter (1973). In transposing Fischer's method, we end up with a similar value to the one found by Fischer ( 0.46 in Toulouse against 0.44 in the Californian study), varying slightly depending on the urban context.

Finally, I did not expect a convergent distribution of role relations. Similar to Californians, kin comprise about two-fifth of the Toulousains' personal networks. Even though they include slightly fewer people identified simply as neighbors, the distributions are very similar. Yet, the southwest is supposed to be a region of France where kinship relations remain strong (Le Bras, 1986).

What should we conclude from the similarities between the results obtained by two surveys carried out on different continents 25 years apart? Three interpretations come to mind.

The first is that we are simply dealing with methodological effects. Clearly, these effects exist, as was shown by the effect of limiting the lists of names on the indicator of network size. Calculating the density is also restricted by the procedure used, even though the selection of names in the P3 sub-samples mixes "strong" and "weaker" ties. It remains possible that, as we always chose the first names mentioned, the ties selected in P3 are slightly more intimate than those in $\mathrm{P} 2$. Yet, there are, enough variations of these parameters 
within the two bodies of data (depending on age or social level, for example) for us to think that methodological effects cannot explain all the convergence between the two studies.

The second interpretation is that Toulousains have become more similar to Californians of the 1970s in their way of life and in their social practices. After all, the Toulouse metropolitan area has seen the opening of a dozen American-style fast food restaurants since 1982, the city has become internationalized with the success of its aerospace industry, and it is a city where one now finds many students, executives, etc.. Moreover, the structure of the metropolitan area brings it closer to a North American model: the metropolitan area is not very dense and is spread out. One gets around more by car than in other large French cities. This second explanation makes sense. I can well enough imagine that the same study carried out in the same city in the 1970s would not have obtained the same results. Yet it does not suffice to completely explain the convergence of results.

One must make room then for a third interpretation: relational structures are relatively stable, at least in industrialized countries, and are not very sensitive to context variations such as the ones we have put into play here. The convergence already noticed by Fischer and Shavit's (1995) Israeli study encourages one to give credit to this interpretation. Hennig's (2006) study of contemporary Germany cities and Bastani's (2006) study of metropolitan Tehran in the late 1990s also shows many similarities. If such findings were to be confirmed by other studies, this would mean that network structures have hardly changed at all since the 1970s, in a variety of semi-industrialized, industrialized and post-industrialized milieus. In other words, despite the evolution in communication methods (Wellman and Haythornthwaite, 2002) and in our way of life, the part of social life constituted by social networks has remained relatively stable. This seems especially true when one measures the social networks by using samples of this kind that bring together people from a diverse range of ages and social status.

There are also two interesting differences between Toulouse and northern California. One is the importance of kinship for more highly-educated Toulousains, which may be explained in looking at the specific characteristics of the local population in which many families went from agriculture to high technology over three generations. However, there may be a more general explanation, as both Hennig (2006) in German cities and Bastani (2006) in Tehran also find the predominance of kinship. The real need may be to explain why northern California and Toronto are less dominated by kin. I suspect that immigration to North America and widespread migration within North America are important reasons why there are lower proportions of kinship ties.

The second difference has to do with the higher level of social support indicators in Toulouse. By contrast to northern California, no Toulousain is ever completely isolated. For example, $14 \%$ of Californians cite less than four companions for social activities while only less than $1 \%$ of respondents do in our study. This difference echoes the analysis of Ferrand, et al. (1999). In France, if people have trouble thinking of themselves as being cut off from the rest of society, then it is because they truly are not. 


\section{References}

Bastani, S., 2006. Family Comes First: Men's and Women's Personal Networks in Tehran. Social Networks: this issue.

Bidart, C., 1997. L'amitié, un lien social. La découverte. Paris. (NOT CITED)

Degenne, A. et Lebeaux M.-O., 1991. L'entraide entre les ménages: un facteur d'inégalités sociales ? Sociétés Contemporaines 8, 21-42. (NOT CITED)

Ferrand, A., Mounier, L. and Degenne, A., 1999. The Diversity of Personal Networks in France: Social Stratification and Relational Structures. In: Wellman B. (Ed.), Networks in the Global Village. Life in Contemporary Communities. Westview. 185-224.

Fischer, C. S., 1982. To Dwell Among Friends. University of Chicago Press, Chicago.

Fischer, C. S. and Shavit, Y., 1995. National Differences in Network Density: Israel and the United States. Social Networks 17 (2), 129-145.

Granovetter, M., 1973. The Strength of Weak Ties. American Journal of Sociology, 78: 1360-80.

Grossetti, M. and Bes, M.-P., 2001. Interacting Individuals and Organizations: A Case Study on Cooperation Between Firms and Research Laboratories. In: Kirman A. and Zimmermann J.-B. (Eds), Economics with Heterogeneous Interacting Agents. Springer, 287-302. (NOT CITED)

Grossetti, M., 2002. Relations sociales, espace et mobilités. Report for the Plan Urbanisme Contruction Architecture, "Mobilités et territoires urbains" program, 150 pages. (NOT CITED)

Hennig, M., 2006. Re-Evaluating the Community Question from a German Perspective. Social Networks: this issue.

Héran, F., 1987. Un Monde Sélectif: Les Associations. Économie et Statistique, 208: 17-31.

Héran, F., 1989. La Sociabilité: Une Pratique Culturelle. Économie et Statistique, 216: 3-21.

Le Bras, H., 1985. Les trois France Seuil, Paris. (YEAR DISCREPANCY with CITATION)

Mok, D. and Wellman, B., 2006. Does Distance Matter? Social Networks (this issue)

Sik, E., and Wellman B. 1999. Network Capital in Capitalist, Communist, and Postcommunist Countries In: Wellman B. (Ed.), Networks in the Global Village. Life in Contemporary Communities. Westview. 225-254

Wellman, B., 1979. The Community Question: The Intimate Networks of East Yorkers. American Journal of Sociology, 84 (5), 1201-1231.

Wellman, B. (Ed.), 1999. Networks in the Global Village. Life in Contemporary Communities, Westview.

Wellman, B. and Haythornthwaite, C. (Eds). 2002. The Internet in Everyday Life. Blackwell Oxford.

Wellman, B. and Wortley, S. 1990. Different Strokes From Different Folks. American Journal of Sociology, 96 (11), 558-88. 


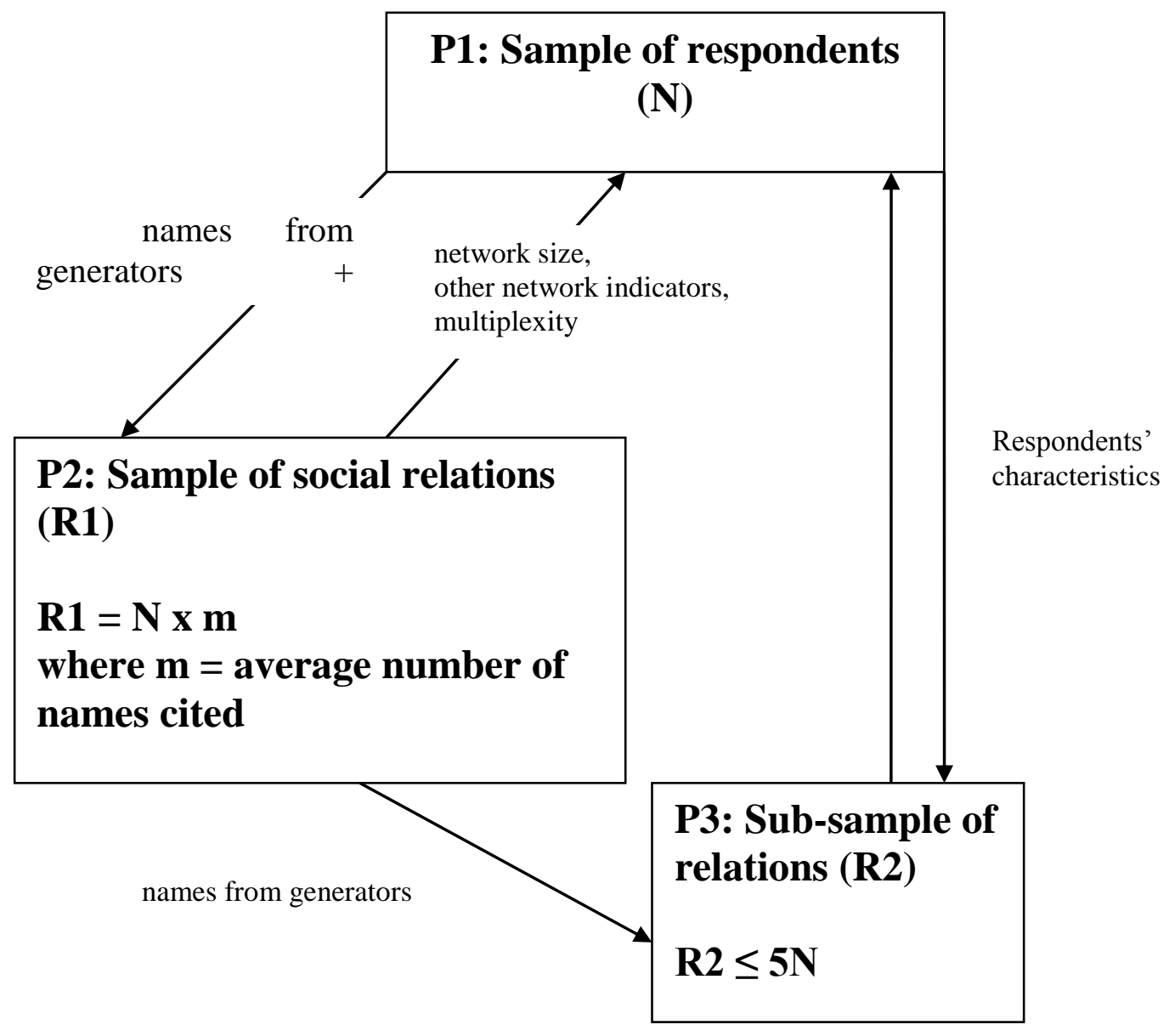

Fig. 1. Interrelationship of Toulouse samples. 


\section{Table 1}

\section{Size and density of northern California and Toulouse samples}

\begin{tabular}{lll}
\hline Characteristics & Northern California, 1977-78 & \multicolumn{1}{c}{ Toulouse. 2001 } \\
\hline Sample & 1,050 persons from northern & 399 persons from Toulouse area \\
& California (50 different & (5 different zones) \\
& locations, \\
& 4 types of urban contexts) &
\end{tabular}

Mean number of persons

12.8

14.6

listed in response to the

(with correction)

name generators

(before additional names)

Mean density

0.44

0.46

Note: Respondents with at least 4 relations in the sub-sample, with no co-housing. 
Table 2

Mean network size by level of education

Level of Education

Mean Number of Names Cited

(corrected data)

Less than the baccalauréat $(<12$ years of school)

Baccalauréat (12 years)

13.10

Baccalauréat +2 (14 years)

14.95

Baccalauréat +4 (16 years)

14.94

Total

ANOVA : $F=10.135 \quad$ Sig. $=0.000(<1 / 10000)$

Mean of squares $=171.774$ between groups and 16.948 intra-groups 
Table 3

Percentage of types of relationships in Toulouse and northern California

\begin{tabular}{lcc}
\hline $\begin{array}{l}\text { Type of } \\
\text { Relationship }\end{array}$ & $\begin{array}{c}\text { Toulouse } \\
\text { (corrected data) }\end{array}$ & Northern California \\
\hline Kin & 36 & 42 \\
Co-workers & 14 & 10 \\
Neighbors & 5 & 10 \\
Organizations & 6 & 6 \\
Friends & $28^{*}$ & 23 \\
Other & 4 & 6 \\
\hline
\end{tabular}

${ }^{*}$ Corrected to take into account a difference in coding: exclusive in northern California; inclusive in Toulouse. California data taken from Fischer (1982: 41). 
Table 4

Percent of network members providing social support

\begin{tabular}{|c|c|c|}
\hline Social Support Indicators & $\begin{array}{c}\text { Northern California, } \\
\text { 1977-78 } \\
\end{array}$ & Toulouse, 2001 \\
\hline \multicolumn{3}{|c|}{ “Counseling” (discussing personal matters; seeking advice) } \\
\hline $\mathbf{0}$ & 15 & 9 \\
\hline 1 & 20 & 10 \\
\hline $2+$ & 65 & 81 \\
\hline \multicolumn{3}{|c|}{ "Companionship" (social activities, discussing hobbies) } \\
\hline 1 or 2 & 3 & 0 \\
\hline 2 or 3 & 11 & 1 \\
\hline $4+$ & 86 & 99 \\
\hline \multicolumn{3}{|c|}{ "Practical support" (home maintenance, discussing work, help with housework, lending money) } \\
\hline 1 or 2 & 6 & 5 \\
\hline 2 or 3 & 19 & 15 \\
\hline $4+$ & 75 & 80 \\
\hline
\end{tabular}

Note: Both samples exclude network members living in the same household. 
Table 5

Percentage of network members living apart from respondents

\section{Within 5 minutes}

drive

Between 5 minutes

and one hour's drive away

40

35

At least one hour's drive

away
25

28

55

(43\% inside the metropolitan area, for respondents from Toulouse only)

(29\% outside the metropolitan area, for respondents from Toulouse only) 
Table 6

Summary: northern California and southwestern France

\begin{tabular}{ccc}
\hline Characteristics & Northern California, 1977-78 & Toulouse 2001 \\
\hline Sample Size & 1,050 respondents & 399 respondents \\
& (50 different locations, 4 types of & (5 different zones)
\end{tabular}

\section{Network Indicators}

\begin{abstract}
Mean number of persons listed in response to the name generators (before additional names)
\end{abstract}

\author{
Mean density* \\ Percent kin \\ Mean multiplexity
}

\author{
Network size and education level \\ Multiplexity and age
}

Type of relation and education level

2+ Advice relations

4+ Companionship relations

4+ Practical Support relations

$$
12.8
$$

14.6 (with correction)
0.46

$35-40$

1.69

\section{Correlations}

Number increases with education level Relations more specialized for older respondents Lower percentage of kin for more highly educated respondents
Number increases with education level Relations more specialized for older respondents Higher percentage of kin relations for lower levels of education but no difference for the others

\section{Social Support}

\section{Spatial Structure of Networks: Percentage of Network Members Living}

\author{
Within 5 minutes' drive \\ Between 5 minutes' drive and one \\ hour's drive
}

More than one hour's drive
25

40

35

$\begin{array}{ll}65 & 81 \\ 86 & 99 \\ 75 & 80\end{array}$
81
99
80

1
9
8

